At least one TESAE (subcutaneous abscess, pulmonary tuberculosis, staphylococcal sepsis, toxic shock syndrome, cervix carcinoma, obstructive pancreatitis, diabetic vascular disorder) was reported in $8(5.6 \%)$ of OKZ groups, numerically higher than $4(2.8 \%)$ in PBO. There was one death due to septic shock in the OKZ q2w arm. Conclusion: Treatment with OKZ over a 24-week period was associated with significant improvements in the signs, symptoms and physical function of RA, with a safety profile consistent with Phase II data for OKZ and with the data for the agents with similar mechanism of action.

There were no discernible differences between the two regimens of OKZ in efficacy or safety outcomes.

References:

[1] Genovese MC et al. Ann Rheum Dis. 2014 Sep; 73:1607; 2. Takeuchi T, et al. Mod Rheumatol. 2016; 26:1

Acknowledgments: Investigators and patients of CREDO-1 study.

Disclosure of Interests: Evgeny Nasonov Speakers bureau: Lilly, AbbVie, Pfizer, Biocad, R-Pharm, Rumen Stoilov Grant/research support from: R-Pharm, Tamara Tyabut: None declared, Mark C. Genovese Grant/research support from: Abbvie, Eli Lilly and Company, EMD Merck Serono, Galapagos, Genentech/ Roche, Gilead Sciences, Inc., GSK, Novartis, Pfizer Inc., RPharm, Sanofi Genzyme, Consultant of: Abbvie, Eli Lilly and Company, EMD Merck Serono, Genentech/Roche, Gilead Sciences, Inc., GSK, Novartis, RPharm, Sanofi Genzyme DOI: 10.1136/annrheumdis-2020-eular.1688

\section{OP0022 RISK OF DIVERTICULITIS AND GASTRO-INTESTINAL PERFORATION IN RHEUMATOID ARTHRITIS TREATED WITH TOCILIZUMAB COMPARED TO RITUXIMAB AND ABATACEPT: A PROSPECTIVE PROPENSITY- MATCHED COHORT STUDY}

C. Rempenault ${ }^{1}$, C. Lukas $^{1}$, B. Combe ${ }^{1}$, T. Schaeverbeke ${ }^{2}$, D. Wendling ${ }^{3}$, T. Pham ${ }^{4}$, X. Mariette ${ }^{5}$, J. E. Gottenberg ${ }^{6}$, J. Morel ${ }^{1} .{ }^{1} \mathrm{CHU}$ and University of Montpellier, Rheumatology, Montpellier, France; ${ }^{2} \mathrm{CHU}$ and University of Bordeaux, Rheumatology, Bordeaux, France; ${ }^{3} \mathrm{CHU}$ and University of Besançon, Rheumatology, Besançon, France; ${ }^{4}$ Aix Marseille Univ, APHM, Rheumatology, Marseille, France; ${ }^{5}$ University Hospital ParisSud, Rheumatology, Paris, France; ${ }^{6} \mathrm{CHU}$ and University of Strasbourg, Rheumatology, Strasbourg, France

Background: There are discordant results regarding a potential increased risk of gastro-intestinal perforation (GIP) in rheumatoid arthritis (RA) patients treated with tocilizumab (TCZ) compared to conventional synthetic disease modifying anti rheumatic drugs (csDMARDs) or TNF inhibitors (TNFis) (1-3).

Objectives: The aim of our study was to compare the risk of diverticulitis and GIP in RA patients treated with TCZ compared to rituximab (RTX) and abatacept (ABA). Methods: We conducted a multicentric study of patients with RA, prospectively followed in 3 observational French registries evaluating the effectiveness and safety of RTX (Autoimmunity and Rituximab (AIR)), ABA (Orencia and Rheumatoid Arthritis (ORA)), and TCZ (REGistry-RoAcTEmra (REGATE)). Using a propensity score approach, we compared the risk of diverticulitis or GIP during treatment with TCZ vs RTX and ABA. The following covariates were included in the propensity score: age, sex, history of diabetes and neoplasia, Charlson Comorbidity Index, number of previous csDMARDs and TNFi, history of TNFi, daily dose of glucocorticoids (GCs) at baseline, co-treatment with a csDMARDs, average DAS28 during follow-up, duration of RA, and exposure time to the considered bDMARDs.

Results: 4501 patients (1496 treated by TCZ, 1986 by RTX and 1019 by ABA) were included. 21 and 9 GIP occurred in the TCZ treated patients, compared to 10 and 8 in the RTX treated patients and 10 and 2 in the ABA treated patients (corresponding incidence rate (IR) are shown in table 1). Two deaths occurred in patients experiencing GIP: 1 (12.5\%) due to undetermined rectal perforation among a RTX treated patient, and $1(11.1 \%)$ due to a perforated ulcer among a TCZ treated patient. Based on inverse probability weighting (IPW), there was an increased risk of diverticulitis and GIP in the TCZ treated patients compared with RTX or ABA (table 1). In a subgroup analysis, we confirmed an increased risk of GIP due to diverticulitis but not to any other etiology. Older age $(p=0.05)$, GCs at baseline $(p=0.10)$ and average daily dose of GCs during follow-up $(p=0.08)$ seemed associated with GIP only in univariate analysis. Compared to RTX and ABA, diverticulitis and GIP among TCZ patients occurred earlier after the last perfusion $(p=0.01)$, with atypical clinical presentation (slow transit in $30 \%, \mathrm{p}=0.04$ ) and lower acute phase reactants when the event occurred (C-reactive protein: $31.2 \pm 58.4$ vs $88.2 \pm 89.6 \mathrm{mg} / \mathrm{L}, \mathrm{p}=0.005$ ). Perforated diverticulitis seemed to have higher dose of GCs at the time of the event compared to diverticulitis without perforation in univariate analysis $(p=0.06)$.

Conclusion: TCZ was associated with an increased risk of diverticulitis, and GIP due to diverticulitis, compared to RTX and ABA. Our study confirms an increased risk of GIP in RA patients treated with TCZ, which might be explained by an increased risk of diverticulitis with misleading clinical presentation.

\section{References:}

[1] Strangfeld A et al. Ann Rheum Dis. 2016 Jul 12

[2] Xie F, Yun $\mathrm{H}$ et al. Arthritis Rheumatol. 2016 May 1

[3] Barbulescu A et al. OP0231, Ann Rheum Dis. 2018 Jun 1;77(Suppl 2):164-5. Disclosure of Interests: Claire Rempenault: None declared, Cédric Lukas: None declared, Bernard Combe Grant/research support from: Novartis, Pfizer, Roche-Chugai, Consultant of: AbbVie; Gilead Sciences, Inc.; Janssen; Eli Lilly and Company; Pfizer; Roche-Chugai; Sanofi, Speakers bureau: Bristol-Myers Squibb; Gilead Sciences, Inc.; Eli Lilly and Company; Merck Sharp \& Dohme; Pfizer; Roche-Chugai; UCB, Thierry Schaeverbeke: None declared, Daniel Wendling: None declared, Thao Pham Speakers bureau: Novartis, Janssen, Lilly, Xavier Mariette Consultant of: BMS, Gilead, Medimmune, Novartis, Pfizer, Servier, UCB, Jacques-Eric Gottenberg Grant/research support from: BMS, Pfizer, Consultant of: BMS, Sanofi-Genzyme, UCB, Speakers bureau: Abbvie, Eli Lilly and Co., Roche, Sanofi-Genzyme, UCB, Jacques Morel: None declared DOI: 10.1136/annrheumdis-2020-eular.3471

\begin{tabular}{|l|l}
\hline OP0023 & PREDICTION OF REMISSION FOR EACH BIOLOGICS \\
BASED ON PATIENT'S CLINICAL INFORMATION \\
BEFORE STARTING BIOLOGICS USING EXPLAINABLE \\
ARTIFICIAL INTELLIGENCE: DATA FROM THE KOREAN \\
COLLEGE OF RHEUMATOLOGY BIOLOGICS REGISTRY
\end{tabular}

B. S. Koo ${ }^{1}$, S. Eun ${ }^{2}$, K. Shin ${ }^{3}$, H. Yoon ${ }^{4}$, C. L. Hong ${ }^{4}$, D. H. Kim ${ }^{5}$, S. Hong ${ }^{6}$, Y G. Kim ${ }^{6}$, C. K. Lee ${ }^{6}$, B. Yoo ${ }^{6}$, J. S. Oh ${ }^{5} .{ }^{1}$ Inje University Seoul Paik Hospital, Inje University College of Medicine, Department of Internal Medicine, Seoul, Korea, Rep. of (South Korea); ${ }^{2}$ KAIST College of Business, Department of Management Engineering, Seoul, Korea, Rep. of (South Korea); ${ }^{3}$ SMG-SNU Boramae Medical Center, Division of Rheumatology, Seoul, Korea, Rep. of (South Korea); ${ }^{4}$ Asan Medical Center, Health Innovation Big Data Center, Asan Institute of Life Sciences, Seoul, Korea, Rep. of (South Korea); ${ }^{5}$ Asan Medical Center, Department of Biomedical informatics, Seoul, Korea, Rep. of (South Korea); ${ }^{6}$ Asan Medical Center, Division of Rheumatology, Department of Internal Medicine, Seoul, Korea, Rep. of (South Korea)

Background: Many studies have identified predictive factors of response to biologics in patients wirh rheumatoid arthritis (RA). However, there is still a lack in using them in daily clinical practice. Therefore, it is necessary to develop a method that can assist the physician in selecting effective biologics.

Objectives: The purpose of this study is to establish machine learning model that predicts remission in patients treated with biologics using data of RA patients from the Korean College of Rheumatology Biologics (KOBIO) registry, and to identify the important features that have the most influence on the response to biologics using explainable artificial intelligence (AI).

Methods: A total of 1,527 patients who started with biologics such as etanercept adalimumab, golimumab, infliximab, abatacept, and tocilizumab from Decembe 2012 to June 2019 were enrolled. Remission was predicted using 46 variables corresponding to baseline profiles at the starting of each biologics. We used five machine learning methods such as lasso, ridge, SVM, random forest, and XGBoost. For explainability of those models, we used Shapley plot to interpret the feature importance for each biologics.

Table 1. Incidence (/1000 PY) and risk of diverticulitis or GIP

\begin{tabular}{|c|c|c|c|c|c|c|c|c|c|c|}
\hline \multirow[b]{3}{*}{ Exposition (PY) } & \multirow[b]{2}{*}{$A E(n)$} & \multirow[b]{2}{*}{ IR } & \multirow[b]{2}{*}{$A E(n)$} & \multirow[b]{2}{*}{ IR } & \multirow[b]{2}{*}{$A E(n)$} & \multirow[b]{2}{*}{ IR } & \multicolumn{4}{|c|}{ IPW analysis } \\
\hline & & & & & & & $\begin{array}{c}\text { OR } \\
{[95 \mathrm{Cl}]}\end{array}$ & $\mathbf{p}$ & $\begin{array}{c}\text { OR } \\
{[95 \mathrm{Cl}]}\end{array}$ & $p$ \\
\hline & \multicolumn{2}{|c|}{$\begin{array}{c}\text { TCZ (ref) } \\
3990\end{array}$} & \multicolumn{2}{|c|}{$\begin{array}{c}\text { RTX } \\
6322\end{array}$} & \multicolumn{2}{|c|}{$\begin{array}{c}\text { ABA } \\
2389\end{array}$} & \multicolumn{2}{|c|}{ TCZ vs RTX } & \multicolumn{2}{|c|}{ TCZ vs ABA } \\
\hline Diverticulitis & 21 & 5.3 & 10 & 1.6 & 10 & 4.2 & $4.5[2.6-7.6]$ & $<0.0001$ & $3.4[1.7-6.5]$ & $<0.0001$ \\
\hline GIP & 9 & 2.3 & 8 & 1.3 & 2 & 0.8 & $2.8[1.5-5.1]$ & 0.001 & $5.4[1.4-19.9]$ & 0.01 \\
\hline * Diverticular GIP & 6 & 1.5 & 3 & 0.5 & 2 & 0.8 & $3.8[1.7-8.5]$ & 0,001 & $6.9[1.9-25.4]$ & 0.004 \\
\hline${ }^{*}$ Due to another etiology & 3 & 0.7 & 5 & 0.8 & 0 & 0 & $1.4[0.5-3.9]$ & 0.5 & - & - \\
\hline
\end{tabular}

$\mathrm{AE}=$ adverse events; $\mathrm{PY}=$ person-years 
Results: In all machine learning methods, the accuracy and the area under the receiver operating characteristic (AUROC) were 57.2\% 74.5\%, 0.547 0.747, respectively (Table 1). The accuracy and AUROC of each biologics were similar between machine learning methods. Figure 2 showed interpretation of feature importance with the Shapley plot for remission. The most important feature was age in adalimumab (younger were closer to remission), daily corticosteroid dose in etanercept, golimumab, and all TNF inhibitors (using fewer doses daily were closer to remission), baseline erythrocyte sedimentation rate in infliximab (lower ESR were closer to remission), disease duration in abatacept (longer disease durations showed difficulty determining remission), baseline c-reactive protein in tocilizumab (higher CRP were closer to remission).

Table 1. Predicting remission for all biologics in various machine learning method.

\begin{tabular}{llllllllll}
\hline & Measure & Lasso & Ridge & SVM & $\begin{array}{c}\text { Random } \\
\text { Forest }\end{array}$ & XGBoost & No info rate & Sample \\
\hline Abatacept & Accuracy & $74.1 \%$ & $74.1 \%$ & $70.6 \%$ & $71.8 \%$ & $68.8 \%$ & $70.6 \%$ & 216 \\
& AUROC & 0.725 & 0.742 & 0.707 & 0.677 & 0.647 & 0.500 & \\
Adalimumab & Accuracy & $73.6 \%$ & $72.0 \%$ & $70.4 \%$ & $72.0 \%$ & $70.4 \%$ & $68.8 \%$ & 315 \\
& AUROC & 0.710 & 0.729 & 0.700 & 0.675 & 0.663 & 0.500 & \\
Etanercept & Accuracy & $72.0 \%$ & $72.0 \%$ & $70.0 \%$ & $71.5 \%$ & $70.0 \%$ & $68.0 \%$ & 250 \\
& AUROC & 0.741 & 0.747 & 0.726 & 0.719 & 0.704 & 0.500 & \\
Golimumab & Accuracy & $71.3 \%$ & $68.5 \%$ & $66.7 \%$ & $68.5 \%$ & $68.5 \%$ & $68.5 \%$ & 138 \\
& AUROC & 0.746 & 0.727 & 0.701 & 0.690 & 0.655 & 0.500 & \\
TNFiximab inhibitors & Accuracy & $72.8 \%$ & $73.5 \%$ & $67.6 \%$ & $73.5 \%$ & $69.1 \%$ & $72.5 \%$ & 172 \\
& AUROC & 0.663 & 0.683 & 0.616 & 0.597 & 0.527 & 0.500 & \\
Tocilizumab & Accuracy & $73.9 \%$ & $74.5 \%$ & $73.9 \%$ & $74.2 \%$ & $73.6 \%$ & $70.3 \%$ & 875 \\
& AUROC & 0.739 & 0.741 & 0.726 & 0.747 & 0.724 & 0.500 & \\
& Accuracy & $62.4 \%$ & $63.6 \%$ & $62.4 \%$ & $59.5 \%$ & $57.2 \%$ & $59.5 \%$ & 436 \\
& AUROC & 0.633 & 0.640 & 0.633 & 0.615 & 0.547 & 0.500 & \\
\hline
\end{tabular}
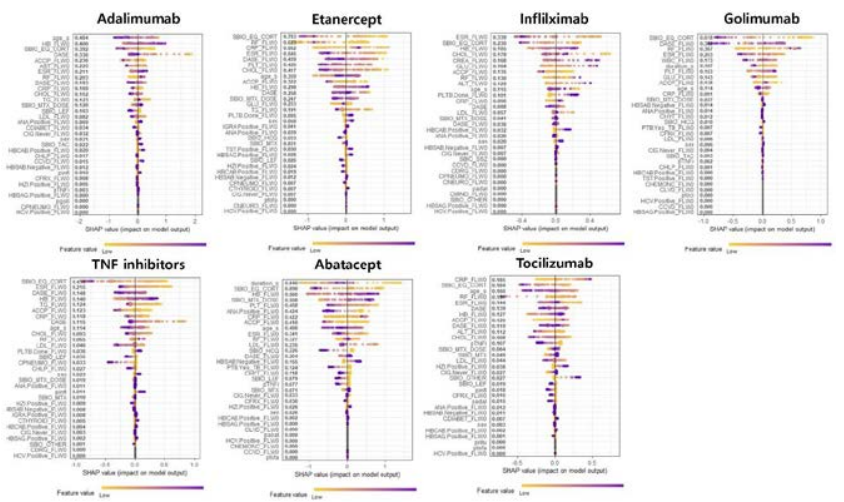

Figure 2. Shapley plots and SHAP values for the feature importance from clinical information in patients with RA.

Conclusion: We developed machine learning models for predicting remission as a response to each biologics in active RA patients based on their clinical profiles, and found important clinical features using explainable Al. This approach may support clinical decisions to improve treatment outcomes in patients with RA.

Disclosure of Interests: None declared

DOI: 10.1136/annrheumdis-2020-eular.3438

\section{OP0024 USE OF HYDROXYCHLOROQUINE AND RISK OF HEART FAILURE IN PATIENTS WITH RHEUMATOID ARTHRITIS}

A. Sorour ${ }^{1}$, Y. Shahin ${ }^{1}$, C. S. Crowson ${ }^{2}$, R. Kurmann ${ }^{1}$, S. Achenbach ${ }^{2}$, R. Mankad ${ }^{1}$, E. Myasoedova ${ }^{3} .{ }^{1}$ Mayo Clinic, Cardiovascular diseases, Rochester, United States of America; ${ }^{2}$ Mayo Clinic, Biomedical Statistics and Informatics, Rochester, United States of America; ${ }^{3}$ Mayo Clinic, Rheumatology, Rochester, United States of America

Background: Hydroxychloroquine ( $\mathrm{HCQ}$ ) is a disease-modifying anti-rheumatic drug (DMARD) used as a long-term treatment for rheumatoid arthritis (RA) patients. Cardiotoxicity is a rare but potentially life-threatening side effect of $\mathrm{HCQ}$ and may present as conduction disorders, cardiomyopathy, and resulting heart failure (HF). The evidence of cardiotoxicity associated with the use of HCQ largely relies on case reports and case series while large cohort studies on the subject are lacking.

Objectives: To examine the relationship between the use of $\mathrm{HCQ}$ and risk of developing HF in RA.

Methods: In this nested case-control study, cases were Olmsted county, Minnesota residents with incident RA (based on 1987 ACR criteria) in 1980-2013 who developed HF after RA incidence. Each case was matched on year of birth, sex and year of RA incidence with an RA control who did not develop HF. Each non-HF control was assigned an index date corresponding to the HF diagnosis date of the case. Controls were allowed to later become cases to avoid bias. HF was defined using the Framingham criteria. Data on HCQ use including start and stop dates and dose changes was manually abstracted via medical record review, and used to calculate HCQ duration and cumulative dose. Age-adjusted logistic regression models were used to examine the association between HCQ and HF. Results: From a cohort of 1078 subjects, the study identified 143 RA cases diagnosed with HF (mean age 65.8, 62\% females) and 143 non-HF RA controls (mean age 64.5 $62 \%$ female). Cases and controls had similar RA duration, proportion of patients positive for rheumatoid factor (RF) and/ or cyclic citrullinated antibody (CCP), body mass index, and smoking status (Table). The duration of HCQ use prior to the diagnosis of HF was 2.8 years in cases and 2.6 years in controls. A total of 71 cases and 69 controls used $\mathrm{HCQ}$ at some time before index date. Among these, the median (interquartile range) duration of $\mathrm{HCQ}$ use was $2.8(0.6,10.0)$ years for cases and $2.5(0.7,8.2)$ for controls The median cumulative dose of $\mathrm{HCQ}$ was $371 \mathrm{~g}$ and $302 \mathrm{~g}$ in cases and controls, respectively, with $55 \%$ of cases receiving a cumulative dose of $\geq 300 \mathrm{~g}$ compared to $54 \%$ in controls. $\mathrm{HCQ}$ cumulative dose was not associated with $\mathrm{HF}$ (Odds Ratio [OR]: 0.96 per $100 \mathrm{~g}$ increase in cumulative dose, 95\% confidence interval [95\% Cl]: 0.90-1.03). Likewise, no association was found for patients with a cumulative dose $\geq 300 \mathrm{~g}$ (OR 0.92, 95\% Cl 0.412.08). The duration of use of HCQ prior to index was not associated with HF (OR 0.98 $95 \% \mathrm{Cl} 0.91-1.05)$. Retinal toxicity rates were similar in cases and controls.

Table. Characteristics of patients with rheumatoid arthritis with and without heart failure.

\begin{tabular}{lcc}
\hline Variable & $\mathrm{HF}$ & non-HF \\
\hline Age at RA diagnosis (years) & $65.8 \pm 12.3$ & $64.5 \pm 12.5$ \\
Female & $62 \%$ & $62 \%$ \\
RA duration at baseline (years) & $11.3 \pm 8.5$ & $10.3 \pm 8.2$ \\
RF positive & $66 \%$ & $65 \%$ \\
CCP positive & $46 \%$ & $53 \%$ \\
RF/ CCP positive & $68 \%$ & $66 \%$ \\
BMI (at RA diagnosis) & $28.6 \pm 6.5$ & $27.7 \pm 5.4$ \\
Smoking status at RA incidence & $45 \%$ & $41 \%$ \\
Former & $22 \%$ & $22 \%$ \\
Current & & \\
\hline
\end{tabular}

Conclusion: Use of HCQ was not associated with development of HF in patients with RA in this study. While there was no statistically significant association between the cumulative dose of $\mathrm{HCQ}$ and $\mathrm{HF}$, the confidence interval for $\mathrm{HCQ}$ dose $\geq 300 \mathrm{~g}$ was wide suggesting that more studies are needed to understand the impact of higher doses of HCQ on development of HF in RA.

Disclosure of Interests: Ahmed Sorour: None declared, Youssef Shahin: None declared, Cynthia S. Crowson Grant/research support from: Pfizer research grant, Reto Kurmann: None declared, Sara Achenbach: None declared, Rekha Mankad: None declared, Elena Myasoedova: None declared DOI: 10.1136/annrheumdis-2020-eular.625

\section{OP0025 DRUG RETENTION OF 7 BIOLOGICS AND TOFACITINIB IN BIOLOGICS-NAÏVE AND BIOLOGICS-SWITCHED PATIENTS WITH RHEUMATOID ARTHRITIS -THE ANSWER COHORT STUDY}

K. Ebina ${ }^{1}$, T. Hirano ${ }^{2}$, Y. Maeda ${ }^{2}$, W. Yamamoto ${ }^{3,4}$, M. Hashimoto ${ }^{4}$, K. Murata ${ }^{4}$, T. Takeuchi ${ }^{5}$, H. Shiba ${ }^{5}$, Y. Son ${ }^{6}$, H. Amuro ${ }^{6}$, A. Onishi ${ }^{7}$, K. Akashi ${ }^{7}$, R. Hara ${ }^{8}$, M. Katayama ${ }^{9}$, K. Yamamoto ${ }^{10}$, A. Kumanogoh ${ }^{2}$, M. Hirao ${ }^{11} .{ }^{1}$ Osaka University, Graduate School of Medicine, Department of Musculoskeletal Regenerative Medicine, Osaka, Japan; ${ }^{2}$ Osaka University, Graduate School of Medicine, Department of Respiratory Medicine and Clinical Immunology, Osaka, Japan; ${ }^{3}$ Kurashiki Sweet Hospital, Department of Health Information Management, Okayama, Japan; ${ }^{4}$ Graduate School of Medicine, Kyoto University, Department of Advanced Medicine for Rheumatic Diseases, Kyoto, Japan; ${ }^{5}$ Osaka Medical College, Department of Internal Medicine (4), Osaka, Japan; ${ }^{6}$ Kansai Medical University, First Department of Internal Medicine, Osaka, Japan; ${ }^{7}$ Kobe University Graduate School of Medicine, Department of Rheumatology and Clinical Immunology, Hyogo, Japan; ${ }^{8}$ Nara Medical University, The Center for Rheumatic Diseases, Nara, Japan; ${ }^{9}$ Osaka Red Cross Hospital, Department of Rheumatology, Osaka, Japan; ${ }^{10}$ Wakayama Medical University Hospital, Department of Medical Informatics, Wakayama, Japan; ${ }^{11}$ Osaka University, Graduate School of Medicine, Department of Orthopaedic Surgery, Osaka, Japan

Background: EULAR recommendation announced that biological disease-modifying antirheumatic drugs (bDMARDs) and janus kinase inhibitors (JAKi) are considered as equivalent in the treatment of rheumatoid arthritis (RA). However we still lack reliable evidence of direct comparison between these agents' retention, which may reflect both effectiveness and safety. 